\title{
Effect of surgical revascularization of a right coronary artery tributary of an infarcted nonischemic territory on the outcome of patients with three-vessel disease: A prospective randomized trial
}

\author{
Mario Gaudino, MD \\ Francesco Alessandrini, MD \\ Franco Glieca, MD \\ Nicola Luciani, MD \\ Carlo Cellini, MD \\ Claudio Pragliola, MD \\ Mauro Morelli, MD \\ Fabiana Girola, MD \\ Gianfederico Possati, MD
}

From the Department of Cardiac Surgery, Catholic University, Rome, Italy.

Received for publication July 5, 2003; revisions requested Aug 5, 2003; revisions received Aug 21, 2003; accepted for publication Aug 26, 2003.

Address for reprints: Mario Gaudino, MD, Divisione di Cardiochirurgia, Policlinico Universitario A. Gemelli, Largo A. Gemelli 8, 00168 Rome, Italy (E-mail: mgaudino@ tiscali.it).

J Thorac Cardiovasc Surg 2004;127:435-9 $0022-5223 / \$ 30.00$

Copyright $\odot 2004$ by The American Association for Thoracic Surgery

doi:10.1016/j.jtcvs.2003.08.026
Background: We evaluated the in-hospital and long-term effects of surgical grafting of a dominant graftable right coronary artery tributary of an infarcted nonischemic territory in patients with triple-vessel disease who were undergoing coronary artery bypass grafting.

Methods: Of 303 consecutive patients undergoing coronary artery bypass grafting with 3-vessel coronary disease and a dominant right coronary artery tributary of an infarcted nonischemic territory, 154 were randomized to right coronary artery revascularization and 149 to no right coronary artery grafting. In all cases, standard on-pump surgical myocardial revascularization was performed.

Results: Overall hospital mortality was 2 of 154 versus 1 of $149(P=.97)$; no difference in in-hospital outcome was observed between the 2 groups. At follow-up, cardiac event-free survival was 84 of 152 in the right coronary artery grafting series and 62 of 148 in the non-right coronary artery grafting group $(P=.20)$. However, when the analysis was limited to surviving patients without new scintigraphic evidence of ischemia (to avoid confounding factors derived from ischemia in the left coronary system or right coronary artery graft malfunction), we found that patients who received a right coronary artery graft had fewer cardiac events, a lower incidence of arrhythmia, and less left ventricular dilatation than did the non-right coronary artery revascularized series.

Conclusions: Surgical grafting of a right coronary artery tributary of an infarcted nonischemic territory in patients with 3-vessel coronary artery disease submitted to coronary artery bypass grafting improved late electric stability, ventricular geometry, and event-free survival but did not affect in-hospital or 10-year survival.

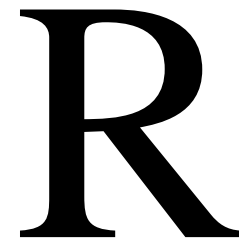

evascularization of all diseased vessels has traditionally been considered the gold standard during coronary artery bypass grafting procedures $(\mathrm{CABG})$, and several studies have documented the benefits of this type of revascularization strategy in terms of survival and quality of life. ${ }^{1,2}$

However, most of these investigations were performed in an early era of coronary surgery, when preoperative determination of the functional status of the myocardium was rarely performed. In more recent years, the wide 


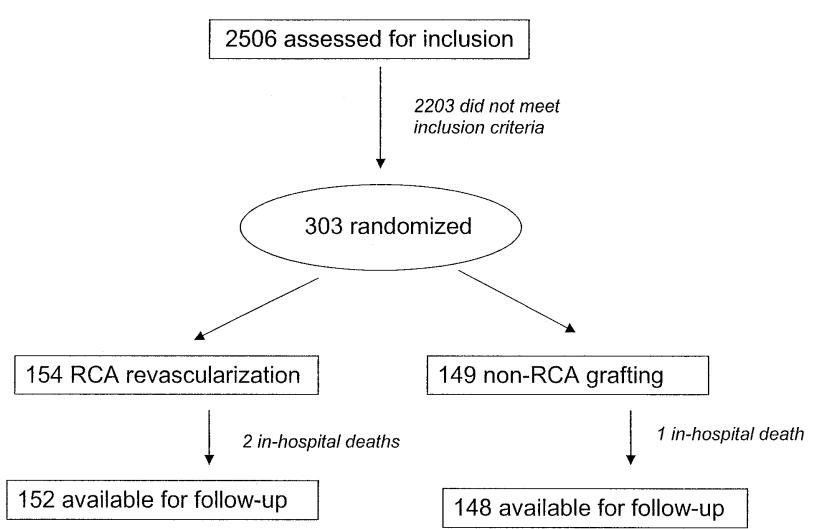

Figure 1. Trial profile.

diffusion and availability of new imaging techniques led to the possibility of functionally evaluating the myocardium and suggested the possibility of a revascularization strategy limited to ischemic areas.

This prospective, randomized investigation was conceived to establish the effect of surgical revascularization of an infarcted nonischemic territory. To maximize homogeneity and to reduce confounding factors, we decided to isolate only the right coronary artery (RCA) as a study variable and, then, to evaluate the in-hospital and long-term effects of the surgical grafting of a dominant graftable RCA tributary of an infarcted nonischemic territory in patients with triple-vessel disease who were undergoing CABG.

\section{Patients and Methods}

\section{Patient Population}

This investigation received local institutional review board approval, and each patient gave informed consent to participate in the protocol. All patient data were prospectively collected and stored in a computerized database.

The population of the study included all patients who underwent CABG by the same surgeon at our institution from January 1990 to December 1994 and who fulfilled the following inclusion criteria at the time of operation:

1. Primary elective isolated CABG.

2. Angiographic evidence of triple-vessel coronary artery disease with a diseased dominant graftable RCA.

3. Previous transmural inferior myocardial infarction with a $Q$ wave on the inferior leads of a surface electrocardiogram.

4. Echocardiographic evidence of inferior akinesia or dyskinesia.

5. Absence of inducible ischemia in the RCA territory during preoperative thallium 201 stress myocardial scintigraphy. Scintigraphic data were analyzed according to a described methodology. ${ }^{3}$

Patients were then randomly assigned by the operating surgeon to receive or not receive surgical revascularization of the RCA or one of its branches, according to a computer-generated sequence. Overall, 303 of the 2506 coronary cases operated on during the
TABLE 1. Preoperative and Intraoperative characteristics of the patients of the 2 groups

\begin{tabular}{lccc}
\hline Variable & $\begin{array}{c}\text { RCA grafting } \\
\text { (n = 154) }\end{array}$ & $\begin{array}{c}\text { Non-RCA } \\
\text { grafting } \\
\text { (n= 149) }\end{array}$ & $\boldsymbol{P}$ value \\
\hline Age (y) & $63 \pm 6$ & $62 \pm 8$ & .21 \\
Men & 91 & 83 & .83 \\
Smokers & 64 & 59 & .90 \\
Hypercholesterolemia & 49 & 52 & .77 \\
Hypertension & 87 & 85 & .96 \\
Diabetes & 33 & 28 & .74 \\
Bypass conduits & & & \\
$\quad$ LITA + GSV (s) and/or LRA & 143 & 140 & .98 \\
$\quad$ GSV (s) & 11 & 9 & .89 \\
Mean LVEF & $51 \pm 11$ & $53 \pm 10$ & .10 \\
Bypass/patient & $3.1 \pm 0.9$ & $2.2 \pm 0.7$ & $<.001$ \\
CPB time (min) & $76 \pm 15$ & $61 \pm 19$ & $<.0001$ \\
Aortic clamp time (min) & $71 \pm 12$ & $57 \pm 15$ & $<.0001$ \\
\hline
\end{tabular}

LITA, Left internal thoracic artery; $R C A$, right coronary artery; GSV, great saphenous vein; $L R A$, left radial artery; $L V E F$, left ventricular ejection fraction; $C P B$, cardiopulmonary bypass.

study period were included: 154 were assigned to RCA revascularization, whereas 149 were assigned to no RCA grafting (Figure 1).

The main features of the patients are summarized in Table 1; no significant differences in terms of preoperative or intraoperative characteristics were found between the 2 groups, although patients in whom the RCA was not revascularized had shorter cardiopulmonary bypass and crossclamp times and, obviously, fewer grafts per patient. Complete revascularization of the left coronary system was considered mandatory and was achieved in all patients.

\section{Surgical Technique}

Surgical revascularization was performed by following a standardized method with median sternotomy, cardiopulmonary bypass, and cardioplegic arrest. No major change in intraoperative or postoperative protocols was introduced during the study period. The left internal thoracic artery was used for the left anterior descending artery, and complementary venous or radial artery grafts were used for non-left anterior descending artery target vessels.

\section{Follow-up}

Each patient was followed up regularly at our institution 6 months after surgery and every year thereafter. At each time interval, clinical examination was performed, and the results of surface electrocardiography, stress thallium 201 myocardial scintigraphy, 24-hour Holter monitoring, and transthoracic echocardiography were carefully reviewed. Angiographic follow-up was proposed to the patients in case of scintigraphic evidence of inducible ischemia.

For the purposes of this study, all patients were telephoned and were resubmitted to clinical examination; all examinations were reviewed at the time of the follow-up. In case of death, all available clinical data were collected and reviewed by the authors to establish the cause of the fatality. Death was considered cardiac in 
origin when it was preceded by objective evidence of myocardial ischemia or arrhythmia and was considered noncardiac when a clear systemic or accidental cause of death was evident. Follow-up was $100 \%$ complete (300/300 surviving patients), and mean follow-up time was $119 \pm 7$ months.

\section{End Point Definitions}

Primary end points were death, cardiac death, and event-free survival (included as events: death, cardiac death, clinical angina recurrence, and new scintigraphic evidence of ischemia).

Secondary end points (to be evaluated only in surviving patients without new scintigraphic evidence of ischemia during the follow-up) were rehospitalization for heart failure, clinically evident ventricular arrhythmia, perioperative modification of left ventricular dimensions and ejection fraction, and development of new mitral insufficiency greater than or equal to grade $1+$.

\section{Statistical Analysis}

Data are expressed as mean \pm SD. Statistical analysis comparing 2 groups was performed with unpaired 2-tailed $t$ testing for the means or with the $\chi^{2}$ test for categorical variables.

To avoid bias related to RCA graft malfunction in the RCA revascularization group and in an attempt to isolate the effect of RCA revascularization alone and minimize confounding factors related to ischemia in the left coronary system, we performed a separate comparison of follow-up data with the exclusion of all patients in whom new scintigraphic evidence of ischemia developed during the follow-up period. Analysis was conducted by the software Statistica for Windows 4.1 (StatSoft Inc, Tulsa, Okla).

\section{Results}

\section{In-Hospital Results}

Mortality and morbidity data are summarized in Table 2. Three patients died in the hospital: 2 from the RCA grafting group and 1 in the non-RCA grafting series $(P=.97)$. Causes of postoperative death were stroke and myocardial infarction in the RCA grafting series and respiratory insufficiency in the non-RCA grafting group. Five patients ( 3 in the RCA revascularized group and 2 who did not receive RCA grafting) had a postoperative myocardial infarction, and 2 ( 1 for each group) had perioperative stroke. No significant difference in mortality or morbidity was found between patients of the 2 groups, and, similarly, the mean stays in the intensive care unit and in the hospital after surgery were comparable in the 2 series.

\section{Follow-up Data}

During the follow-up period, 58 patients died (31 from the RCA grafting and 27 from the non-RCA grafting series; $P$ $=.80$; Figure 2 ). The cause of death was cardiac in 29 cases (16 in the RCA grafting vs 13 in the non-RCA grafting group; $P=.78$ ) and noncardiac in 25 . In the remaining 4 cases, the cause of death could not be established with certainty because of the incompleteness of the available documentation.
TABLE 2. In-hospital outcome of the patients of the 2 groups

\begin{tabular}{lccc}
\hline Variable & $\begin{array}{c}\text { RCA grafting } \\
\text { (n= 154) }\end{array}$ & $\begin{array}{c}\text { Non-RCA } \\
\text { grafting } \\
\text { (n= 149) }\end{array}$ & $\boldsymbol{P}$ value \\
\hline Death & 2 & 1 & .97 \\
Myocardial infarction & 3 & 2 & .96 \\
Stroke & 1 & 1 & .49 \\
Postoperative need for dialysis & 1 & 0 & .98 \\
Mechanical ventilation $>24 \mathrm{~h}$ & 11 & 13 & .79 \\
Revision for bleeding & 3 & 3 & .71 \\
Mean intensive care stay (h) & $26.2 \pm 5.6$ & $27.1 \pm 4.8$ & .13 \\
Mean in-hospital stay (d) & $5.0 \pm 1.2$ & $5.2 \pm 0.8$ & .61
\end{tabular}

$R C A$, Right coronary artery.

New scintigraphic evidence of ischemia was found in 50 cases (27 in the RCA grafting vs 23 in the non-RCA grafting group; $P=.77$ ). Thirty-four of these patients (19 RCA grafting and 15 non-RCA grafting series) agreed to undergo follow-up coronary angiography at a mean interval of $64 \pm 19$ months from operation. The results of these postoperative angiograms are reported in Table 3. In 23 cases (14 from the RCA grafting series), graft malfunction was the cause of ischemia, whereas in the remaining 11 (5 from the RCA grafting series), progression of coronary disease was responsible for ischemia recurrence.

Overall, cardiac event-free survival at a mean follow-up of $119 \pm 7$ months was 84 of 152 in the RCA grafting series and 62 of 148 in the non-RCA grafting group $(P=.20)$. However, when the analysis was limited to surviving patients without new scintigraphic evidence of ischemia during the follow-up (94 in the RCA revascularization series and 98 in the non-RCA grafting group), it became apparent that patients who received an RCA graft at the time of operation had fewer cardiac events (in particular, rehospitalization for heart failure) and a lower incidence of arrhythmia compared with the non-RCA revascularization series (Table 4).

Moreover, echocardiographic follow-up demonstrated that patients in whom the RCA was left untouched at the time of CABG had larger postoperative ventricular volumes and were more likely to experience development of new mitral regurgitation greater than or equal to grade $1+$ (Table 4).

\section{Discussion}

Since the early days of coronary artery surgery, grafting of all diseased vessels has been considered necessary. ${ }^{1,2}$ However, the successive possibility of obtaining an exact preoperative determination of the functional status of the myocardium suggested the possibility of revascularizing only those vessels in the distribution of ischemic areas, leaving untouched the coronary vessels that served infarcted nonischemic territories. 




Figure 2. Postoperative survival in the 2 groups of patients.

TABLE 3. Results of postoperative angiograms

\begin{tabular}{lcc}
\hline Variable & $\begin{array}{c}\text { RCA grafting } \\
\text { (n = 19) }\end{array}$ & $\begin{array}{c}\text { Non-RCA } \\
\text { grafting } \\
\text { (n= 15) }\end{array}$ \\
\hline Graft malfunction & 14 & 9 \\
LITA/LAD & 2 & 3 \\
GSV/OM & 8 & 4 \\
GSV/D1 & 2 & 2 \\
GSV/AL & 2 & 0 \\
Coronary artery disease progression & 5 & 6 \\
LAD & 4 & 2 \\
CX & 0 & 4 \\
RCA & 1 & 0 \\
\hline
\end{tabular}

LITA, Left internal thoracic artery; $R C A$, right coronary artery; $L A D$, left anterior descending artery; GSV, great saphenous vein; $O M$, obtuse marginal branch; $D 1$, first diagonal branch; $A L$, anterolateral branch $C X$, circumflex artery.

Although some interventional cardiologist groups reported good results, doubts about the efficacy of this limited revascularization policy have been elicited by several authors, and the results of this strategy applied to surgical revascularization procedures were never investigated in detail. ${ }^{4-7}$ Our study was designed with the aim of establishing the immediate and long-term effects of surgical grafting of a vessel tributary of an infarcted nonischemic (scarred) myocardial territory.

Because the heterogeneity of patients with coronary artery disease submitted to CABG renders extremely difficult the task of avoiding confounding factors in the elaboration of a comparison between different treatments, every effort was made to minimize potential bias. First, a prospective randomized design was judged necessary. Moreover, the operating surgeon and the surgical technique were always
TABLE 4. Long-term outcome of the surviving patients of the 2 groups without new scintigraphic evidence of ischemia during the follow-up

\begin{tabular}{|c|c|c|c|}
\hline Variable & $\begin{array}{l}\text { RCA grafting } \\
(\mathrm{n}=94)\end{array}$ & $\begin{array}{c}\text { Non-RCA } \\
\text { grafting } \\
(\mathrm{n}=98)\end{array}$ & $P$ value \\
\hline $\begin{array}{l}\text { Rehospitalization for heart failure } \\
\text { Clinically evident ventricular }\end{array}$ & 4 & 15 & .03 \\
\hline $\begin{array}{l}\text { arrhythmia* } \\
\text { Echocardiography data }\end{array}$ & 6 & 21 & .01 \\
\hline $\begin{array}{l}\text { LVEF } \\
\text { Preoperative } \\
\text { Follow-up }\end{array}$ & $\begin{array}{l}51 \pm 11 \\
58 \pm 9\end{array}$ & $\begin{array}{l}53 \pm 10 \\
54 \pm 6\end{array}$ & $\begin{array}{c}.10 \\
<.0001\end{array}$ \\
\hline $\begin{array}{l}\text { EDVI }\left(\mathrm{mL} / \mathrm{m}^{2}\right) \\
\text { Preoperative } \\
\text { Follow-up }\end{array}$ & $\begin{array}{l}73 \pm 12 \\
71 \pm 9\end{array}$ & $\begin{array}{l}72 \pm 11 \\
83 \pm 12\end{array}$ & $\begin{array}{c}.45 \\
<.0001\end{array}$ \\
\hline ESVI $\left(\mathrm{mL} / \mathrm{m}^{2}\right)$ & & & \\
\hline $\begin{array}{l}\text { Preoperative } \\
\text { Follow-up } \\
\text { lew mitral insufficiency } \geq 1\end{array}$ & $\begin{array}{l}38 \pm 11 \\
36 \pm 8 \\
5\end{array}$ & $\begin{array}{l}37 \pm 9 \\
41 \pm 11 \\
17\end{array}$ & $\begin{array}{c}.39 \\
<.0001 \\
.03\end{array}$ \\
\hline
\end{tabular}

$E D V I$, End-diastolic volume index; $E S V I$, end-systolic volume index; $L V E F$, left ventricular ejection fraction; $R C A$, right coronary artery.

*Defined as symptomatic ventricular arrhythmia necessitating medical treatment.

the same to avoid a technical influence on postoperative results. Similarly, to maximize the homogeneity of the study population, we isolated only the RCA as a study variable. Moreover, to eliminate the potential confounding factors related to ischemia in the left coronary system or RCA graft malfunction among RCA-revascularized patients, we added to the analysis of the results of the overall population a separate analysis of the follow-up data with the exclusion of all patients in whom new scintigraphic evidence of ischemia developed during the years after surgery. 
Using this method, we found that RCA-revascularized and non-RCA-revascularized patients had similar postoperative outcomes and did not significantly differ in crude survival in the 10 years after surgery. However, RCArevascularized patients exhibited a trend toward better longterm cardiac event-free survival (84/152 vs $62 / 148$ ); because statistical significance could have been limited by the sample size in our series, it is possible that future larger multi-institutional studies could more clearly demonstrate significant clinical benefits related to RCA grafting. Moreover, RCA revascularization was associated with increased electrophysiological stability and less left ventricular dilatation, as evidenced by the higher incidence of arrhythmia, cardiac events, and heart failure, larger left ventricular volumes, and higher incidence of new mitral regurgitation in the series of patients in whom the RCA was left ungrafted (Table 3).

Clinical and experimental studies have suggested that the benefits of reperfusion of an infarct-related artery extend beyond the simple salvage of ischemic myocardium and favorably affect left ventricular remodeling and electrical stability independently from the functional status of the infarcted myocardium (the open artery hypothesis). ${ }^{8-13}$ Our observations are in accordance with those data and seem to establish the superiority of anatomically complete versus functionally adequate revascularization for patients with triple-vessel disease submitted to CABG (at least in regard to the RCA).

These findings are of particular relevance at a time when the growing diffusion of minimally invasive techniques and beating-heart surgery has led to an increasing acceptance by the surgical community of a revascularization strategy limited to ischemic myocardial areas. ${ }^{14}$ Although we have no information on the effect of revascularization of left coronary system branches feeding into a scar territory, the larger amount of myocardium supplied by the left coronary system should theoretically render the advantages observed for the RCA even more evident.

While waiting for objective verification of this hypothesis, we can conclude that surgical grafting of an RCA tributary of an infarcted nonischemic territory in patients with 3-vessel disease submitted to CABG improves late electric stability and ventricular remodeling and reduces rehospitalization for cardiac events, although it does not affect in-hospital or 10-year survival. Surgical grafting of a diseased RCA should, then, always be attempted, independently from the functional status of the myocardium supplied by the artery.

\section{References}

1. Bell MR, Gersh BJ, Schaff HV, Holmes DR, Fisher LD, Alderman EL, et al. Effect of completeness of revascularization on long-term outcome of patients with three-vessel disease undergoing coronary artery bypass surgery. A report from the Coronary Artery Surgery Study (CASS) Registry. Circulation. 1992;86:446-57.

2. Gohlke H, Gohlke-Barwolf C, Samek L, Sturzenofecker P, Schmuziger M, Roskamm H. Serial exercise testing up to 6 years after coronary bypass surgery: behaviour of exercise parameters in groups with different degrees of revascularization determined by postoperative angiography. Am J Cardiol. 1983;51:1301-6.

3. Go RT, MacIntyre WJ, O'Donnel JK, et al. Transaxial single photon emission computed tomography myocardial imaging with 201-Tl: instrumentation, technical, and clinical aspects. In: Freeman LM, Weissman HS, editors. Nuclear medicine annual. New York: Raven Press; 1985. p. 171-98.

4. Faxon DP, Ghalilli K, Jacobs AK, et al. The degree of revascularization and outcome after multivessel coronary angioplasty. Am Heart J. 1992;123:854-7.

5. Cavallini C, Risica G, Olivari Z, Marton F, Franceschini E, Giommi L. Clinical and angiographic follow-up after coronary angioplasty in patients with two-vessel disease: influence of completeness and adequacy of revascularization on long-term outcome. Am Heart J. 1994; 127:1504-9.

6. Cowley MJ, Vandermael M, Topol E, et al. Is traditionally defined complete revascularization needed for patients with multivessel disease treated by elective coronary angioplasty? J Am Coll Cardiol. 1993;22:1289-97.

7. Kloeter U, Jander NG, Buser PT, Osswald S, Mueller-Brand J, Pfisterer ME. Long-term outcome of angioplasty for multivessel coronary: importance and price of complete revascularization. Int J Cardiol. 2001;79:197-205.

8. Kim C, Braunwald E. Potential benefits of late reperfusion of infarcted myocardium. The open artery hypothesis. Circulation. 1993;88:242636.

9. Boyle MP, Weisman HF. Limitation of infarct expansion and ventricular remodelling by late reperfusion. Study of time course and mechanism in a rat model. Circulation. 1993;88:2872-83.

10. Terada Y, Mitsui T, Matsushita S, Atsumi N, Jikuya T, Sakakibara Y. Influence of bypass grafting to the infarct artery on late potentials in coronary operations. Ann Thorac Surg. 1995;60:422-5.

11. Meneveau N, Bassand JP, Bauters C, et al. Influence of late reopening of the infarct-related artery on left ventricular remodelling after myocardial infarction. Eur Heart J. 1997;18:1261-8.

12. Garot J, Scherrer-Crosbie M, Monin JL, DuPouy P, et al. Effect of delayed percutaneous transluminal coronary angioplasty of occluded coronary arteries after acute myocardial infarction. Am J Cardiol. 1996;77:915-21.

13. Lomama E, Helft G, Persoz A, Vacheron A. Late coronary angioplasty and ventricular late potentials. Am J Cardiol. 1998;82:985-7.

14. Scott R, Blackstone EH, McCarthy P, et al. Isolated bypass grafting of the left internal thoracic artery to the left anterior descending coronary artery: late consequences of incomplete revascularization. J Thorac Cardiovasc Surg. 2000;120:173-84. 